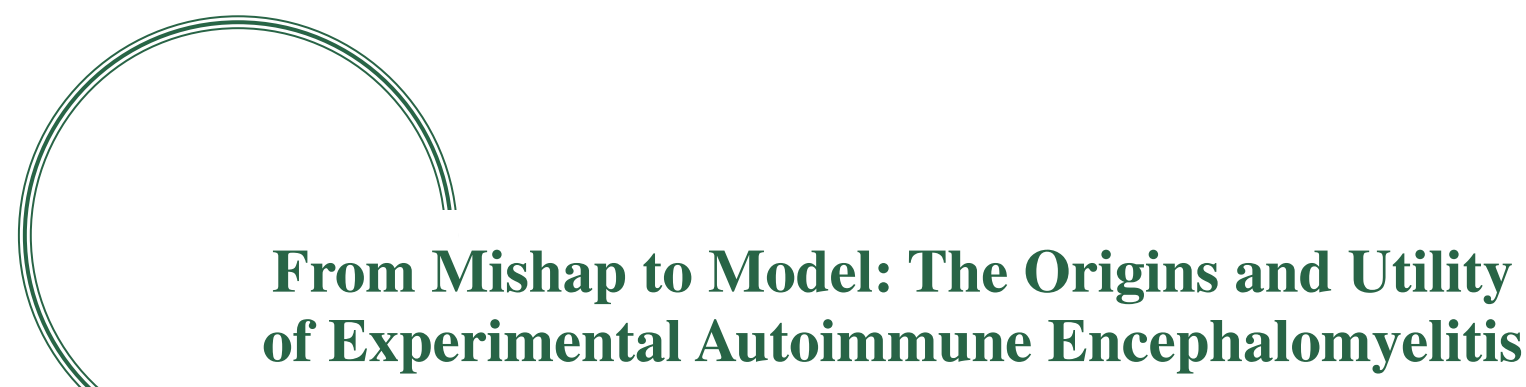

Emma L. Walton

Staff Writer at the Biomedical Journal, 56 Dronningens gate, Trondheim, Norway

This special edition of the Biomedical Journal focuses on experimental autoimmune encephalomyelitis, and includes three reviews showing how this model has greatly facilitated our understanding of the pathophysiology of multiple sclerosis. We also highlight a small single center study which suggests that the use of calcium bone substitutes during core decompression surgery may do more harm than good. Finally, we see how policy changes affect the management of fungal infections in immunocompromised patients and we learn about antibiotic resistance among strains of Streptococcus agalactiae circulating in Taiwan. (Biomed J 2015;38:177-180)

Key words: core decompression, experimental autoimmune encephalomyelitis, multiple sclerosis, osteonecrosis

\section{SPOTLIGHT ON REVIEWS - From Mishap to Model: The Origins and Utility of Experimental Autoimmune Encephalomyelitis}

\begin{abstract}
$\mathrm{A}^{\mathrm{t}}$ $t$ the turn of the $20^{\text {th }}$ century, curious reports started to emerge of cases of paralysis and even death in people treated with Louis Pasteur's rabies vaccine ${ }^{[1]}$ Pasteur had been injecting patients with preparations of spinal cord from rabbits infected with rabies, a practice which Thomas M. Rivers would show later was the direct cause of crippling neurological complications and myelin degeneration in the brain and spinal cord. ${ }^{[2]}$ Today, his work forms the basis for the best characterized animal model of human autoimmune disease: Experimental autoimmune encephalomyelitis (EAE), in which the injection of central nervous system (CNS) antigens mixed with dead Mycobacterium tuberculosis elicits an immune response against the CNS that is very similar to that observed in multiple sclerosis (MS) [Figure 1]. This special issue of the Biomedical Journal includes three reviews describing how EAE has improved our understanding of the pathophysiology of MS.
\end{abstract}

First, Florian Kurschus discusses T cell responses in EAE and in particular the central role of T helper cells producing IL-17 (Th17 cells) in the immune attack against the CNS. ${ }^{[3]}$ Th17 cells are recruited early to the CNS following the induction of EAE, ${ }^{[4]}$ where they stimulate the secretion of matrix metalloproteases, cytokines, and chemokines by local tissue cells. In turn, this pool of immunostimulatory molecules attracts more $\mathrm{T}$ cells and myeloid cell populations. Moreover, IL-17 also stimulates endothelial cells to produce reactive oxygen species, which may disrupt the blood-brain barrier Th17 cells can form immune synapses with axons, ${ }^{[5]}$ rapidly leading to axon damage. ${ }^{[6]}$

Neutralizing these rogue T cells may be the best approach to treat MS, but therapies that target $\mathrm{T}$ cells indiscriminately may also limit beneficial immunity. Peptide immunotherapy (PIT), which aims to induce $\mathrm{T}$ cell tolerance through the administration of specific antigen extracts, has been used to treat allergies for years. ${ }^{[7]}$ Stephen Anderton discusses how EAE can be used as a testing ground for PIT to treat patients with MS. ${ }^{[8]}$ Several CNS autoantigens have been extensively characterized in models of EAE 


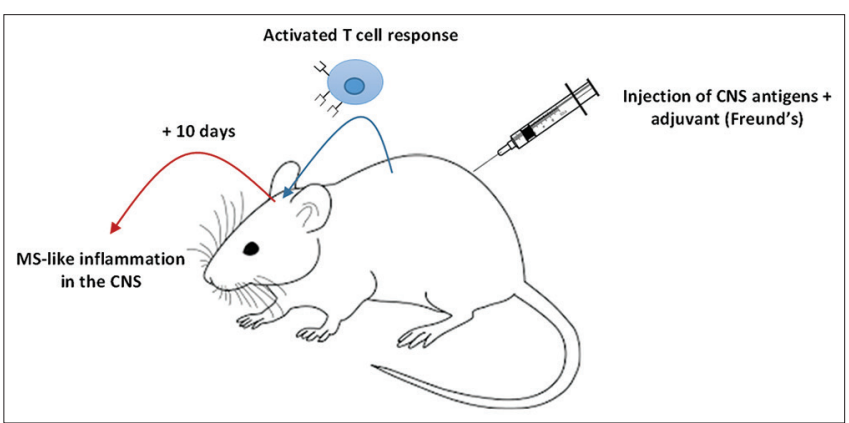

Figure 1: Mouse model of experimental autoimmune encephalomyelitis (EAE). EAE is typically induced by immunization with autoantigens such as myelin oligodendrocyte glycoprotein, myelin basic protein, or proteolipid protein mixed with Freund's adjuvant, which contains high amounts of heat-inactivated Mycobacterium tuberculosis. EAE normally develops after about 10 days and is accompanied by ascending paralysis.

and it has been long known that the intranasal administration of the same peptide that causes EAE, but without adjuvant, can prevent EAE following subsequent immunization. ${ }^{[9]}$ Anderton describes some of the mechanisms behind PIT and points out that the real challenge is not to prevent EAE by PIT, but instead to reverse ongoing EAE, which reflects more the clinical situation in patients with MS.

Finally, Laffont et al. ${ }^{[10]}$ discuss how we can use the EAE model to study the protective effects of estrogen in MS. In women with MS, the disease often subsides temporarily during pregnancy ${ }^{[11]}$ an effect which has been attributed to high levels of estrogens that are produced during this time. Laffont and colleagues describe the cellular targets of estrogen and the mechanisms underlying its neuroprotective and anti-inflammatory effects.

As a shining testament that science really can learn from its mistakes, EAE is the most relevant model of autoimmunity in the CNS and continues to provide hope of a potential cure for the 2.5 million people with MS worldwide.

\section{SPOTLIGHT ON ORIGINAL ARTICLE - Potential Warning over use of Calcium Bone Substitutes in Core Decompression Surgery}

Core decompression surgery is a widely used technique to preserve collapsing bone in people with osteonecrosis. In this issue of the Biomedical Journal, Yu and colleagues report that the use of calcium bone substitutes during this procedure may do more harm than good. ${ }^{[12]}$

Osteonecrosis is a debilitating disease in which reduced blood flow to bones leads to the death of bone tissue and ultimately bone collapse. The disease most commonly affects individuals in midlife, such that joint replacements, which have limited durability, should be avoided if possible. Fortunately, several bone-preserving treatments are available.
One surgical option is core decompression, which involves removing a piece of bone from the affected area to alleviate pressure and to improve blood flow.

To provide mechanical support, synthetic bone substitutes are needed during core decompression. ${ }^{[13]}$ Calcium sulfate $\left(\mathrm{CaSO}_{4}\right)$ and calcium phosphate $\left(\mathrm{CaPO}_{4}\right)$ are bone substitutes that are commonly used to treat fractures and provide stiffness and support to weakened bones. ${ }^{[14,15]}$ In their retrospective analysis, Yu et al., investigate claims that these materials can prevent further bone collapse in patients with osteonecrosis of the femoral head undergoing core decompression surgery.

Yu's team reviewed 18 consecutive patients (19 hips in total) who underwent core decompression surgery combined with a $\mathrm{CaSO}_{4}$ and $\mathrm{CaPO}_{4}$ composite bone substitute at Chang Gung Memorial Hospital in Taiwan in 2008-2009. Clinical function of the hip following surgery was defined by the Harris hip score and clinical failure was defined as a score of $<70$ or conversion to a total hip arthroplasty (THA).

Although their study only included a small number of patients and no control group, the results are nonetheless disheartening. Eleven hips were converted to THAs in an average of only 8.5 months. Only two hips $(10.5 \%)$ survived without further collapse during the 5 year follow-up period and the remaining 17 hips (89.5\%) were either converted to a THA or experienced head collapse within an average of 5.3 months. Pathological analysis of femoral heads removed during THA showed that the bone substitute had failed to harden and there was no evidence of new bone formation.

On paper, the use of $\mathrm{CaSO}_{4} / \mathrm{CaPO}_{4}$ bone substitute during core decompression seems like a good idea. It could fill up the necrotic lesion and harden after cure, thus acting as a scaffold for repair. Moreover, previous studies have shown that these substitutes are gradually absorbed and replaced by new bone. ${ }^{[14]}$ However, some concerns about their efficacy have been raised before in a small animal study of core decompression. ${ }^{[16]}$ Although such substitutes have been successfully used for other indications, Yu et al., hypothesize that the osteonecrotic environment in the femoral head is unsuitable for the synthetic graft to repair the lesion. These findings have already resulted in a change of practice Chang Gung Memorial Hospital. Larger studies are required to determine whether the rest of the world should follow suit.

\section{ORIGINAL ARTICLES - Cataloging Antibiotic Resistance Among Strains of Streptococcus Agalactiae Circulating In Taiwan}

Wang and colleagues catalog the serotypes and antibiotic resistance of $S$. agalactiae,${ }^{[17]}$ which is a common cause of meningitis and infections among newborns. In over 300 
strains isolated from a hospital in Taiwan, resistance to macrolides and clindamycin was widespread. Resistance to fluoroquinolone was rare and associated with mutations in the ParC gene.

\section{Lung Cancer Patients Show Early Response to Personalized Therapy}

Mutations in the epidermal growth factor receptor (EGFR) are common among East Asian female never-smokers with non-small cell lung cancer (NSCLC). ${ }^{[18]}$ Personalized therapy with EGFR tyrosine kinase inhibitors (EGFR-TKIs) is more effective than conventional chemotherapy in these patients, ${ }^{[19]}$ however, it is still unclear when exactly response to EGFR-TKIs should be evaluated. Chang et al. ${ }^{[20]}$ examine response to EGFR-TKIs by medical imaging in 39 patients with NSCLC and show that most patients who respond to treatment show improvement within 14 days.

\section{Examining Heart Rate During Mediation with Poincaré Plots}

Goshvarpour shows that Poincare plots, ${ }^{[21]}$ which are often used to study the nonlinear behavior of physiologic signals, are a useful method to investigate heart rate variability during mediation.

\section{Policy Change May not Prevent More Fungal Infections in Immunocompromised Patients}

Fungal infections are rare in healthy people but can be devastating in immunocompromised individuals. Patients with blood cancers are particularly susceptible, and prophylaxis with anti-fungal agents is often recommended, although this is not without disadvantages ${ }^{[22]}$ In this retrospective study, Devanlay and colleagues investigate whether a change in policy in 2009 regarding the type of prophylaxis used has had an impact on patient management. ${ }^{[23]}$ Their findings suggest that the newly recommended posaconazole does not prevent more fungal infections than fluconazole in patients with acute myeloid leukemia.

\section{The Tea Test: Investigating Discoloration of Acrylic Resins by Spectrophotometry}

Acrylic resin is a popular material for dental bridges but may be prone to discoloration. Kohli and Bhatia put two commonly used brands through rigorous staining tests involving immersion in cola and tea and measurement of color by spectrophotometry. ${ }^{[2]}$ Their findings suggest that tooth molding powder is the best material for lovers of tea who want to maintain a bright smile.

\section{Diagnostic Assays of Hepatitis B Produce Consistent Results}

Levels of hepatitis B surface antigen (HBsAg) may be important for the clinical staging of chronic hepatitis $\mathrm{B}$ infection. ${ }^{[25]}$ Liao and colleagues compare two recently commercialized assays to quantify $\mathrm{HBsAg},{ }^{[26]}$ the Abbott Architect HBsAg qualification test assay and the Roche Elecsys HBsAg II assay, and show that the two assays produce comparable results.

\section{Kyphosis Limits the Success of Posterolateral Fusion Surgery}

Many clinicians disagree about the best surgical method to treat patients with spondylolisthesis. Posterolateral fusion (PLF), in which painful vertebrae are fused into a single bone, is a widely used method, although several factors may influence its outcome. In this retrospective study of $239 \mathrm{pa}-$ tients, Chen et al., ${ }^{[27]}$ show that segmental kyphosis is one such factor. This condition impairs bone fusion following PLF, and alternative techniques are required to overcome this problem.

\section{CORRESPONDENCE - An Unusual Case of Neurilemmoma}

Neurilemmomas are benign, encapsulated tumors of the nerve sheath. In this case report, Bharti et al. ${ }^{[28]}$ describe the unusual case of a neurilemmoma of the nose in a young adult. Their findings suggest that neurilemmoma should be considered to be a differential diagnosis for masses of the nasal cavity.

\section{REFERENCES}

1. Stuart G, Krikorian KS. The neuro-paralytic accidents of anti-rabies treatment. Ann Trop Med 1928;22:327-77.

2. Rivers TM, Schwentker FF. Encephalomyelitis accompanied by myelin destruction experimentally produced in monkeys. J Exp Med 1935;61:689-702.

3. Kurschus FC. T cell mediated pathogenesis in EAE: Molecular mechanisms. Biomed J 2015;38:183-93.

4. Korn T, Reddy J, Gao W, Bettelli E, Awasthi A, Petersen TR, et al. Myelin-specific regulatory T cells accumulate in the CNS but fail to control autoimmune inflammation. Nat Med 2007;13:423-31.

5. Huppert J, Closhen D, Croxford A, White R, Kulig P, Pietrowski E, et al. Cellular mechanisms of IL-17-induced blood-brain barrier disruption. FASEB J 2010;24:1023-34.

6. Siffrin V, Radbruch H, Glumm R, Niesner R, Paterka M, Herz J, et al. In vivo imaging of partially reversible th 17 cell-induced neuronal dysfunction in the course of encephalomyelitis. Immunity 2010;33:424-36 
7. Larché M. Peptide immunotherapy for allergic diseases. Allergy 2007;62:325-31

8. Anderton SM. Peptide immunotherapy in experimental autoimmune encephalomyelitis. Biomed J 2015;38:206-14.

9. Metzler B, Wraith DC. Inhibition of experimental autoimmune encephalomyelitis by inhalation but not oral administration of the encephalitogenic peptide: Influence of MHC binding affinity. Int Immunol 1993;5:1159-65.

10. Laffont S, Garnier L, LéLu K, Guéry JC. Estrogen-mediated protection of experimental autoimmune encephalomyelitis: Lessons from the dissection of estrogen receptor-signaling in vivo. Biomed J 2015;38:194-205.

11. Confavreux C, Hutchinson M, Hours MM, Cortinovis-Tourniaire $\mathrm{P}$, Moreau T. Rate of pregnancy-related relapse in multiple sclerosis. Pregnancy in Multiple Sclerosis Group. N Engl J Med 1998;339:285-91.

12. Yu PA, Peng KT, Huang TW, Hsu RW, Hsu WH, Lee MS. Injectable synthetic bone graft substitute combined with core decompression in the treatment of advanced osteonecrosis of the femoral head: A 5-year follow-up. Biomed J 2015;38:257-61.

13. Rijnen WH, Gardeniers JW, Buma P, Yamano K, Slooff TJ, Schreurs BW. Treatment of femoral head osteonecrosis using bone impaction grafting. Clin Orthop Relat Res 2003;417:74-83.

14. Urban RM, Turner TM, Hall DJ, Inoue N, Gitelis S. Increased bone formation using calcium sulfate-calcium phosphate composite graft. Clin Orthop Relat Res 2007;459:110-7.

15. Kelly CM, Wilkins RM. Treatment of benign bone lesions with an injectable calcium sulfate-based bone graft substitute. Orthopedics 2004;27 1 Suppl: s131-5.

16. Rijnen WH, Gardeniers JW, Schreurs BW, Buma P. Impacted bone and calcium phosphate cement for repair of femoral head defects: A pilot study. Clin Orthop Relat Res 2007;459:216-21.

17. Wang YH, Chen CL, Hou JN, Wang YR, Lin TY, Chiu CH, et al. Serotype distribution and resistance genes associated with macrolide and fluoroquinolone resistance in Streptococcus agalactiae isolates from a hospital in Southern Taiwan. Biomed J 2015;38:215-20.

18. Available from: https://www.letstestnow.com/biomarkers in nsclc/ incidence_of_biomarkers_folder/incidence in subpopulations. html. [Last accessed on 2015 May 29].

19. Kris MG, Natale RB, Herbst RS, Lynch TJ Jr, Prager D, Belani CP, et al. Efficacy of gefitinib, an inhibitor of the epidermal growth factor receptor tyrosine kinase, in symptomatic patients with non-small cell lung cancer: A randomized trial. JAMA 2003 22;290:2149-58.

20. Chang JW, Hou MM, Hsieh JJ, Cheung YC, Wang HM, Huang SF, et al. Early radiographic response to epidermal growth factor receptor-tyrosine kinase inhibitor in non-small cell lung cancer patients with epidermal growth factor receptor mutations: A prospective study. Biomed J 2015;38:221-8.

21. Goshvarpour A, Goshvarpour A. Poincare indices for analyzing meditative heart rate signals. Biomed J 2015;38:229-34.

22. De Pauw BE, Donnelly JP. Prophylaxis and aspergillosis - Has the principle been proven? N Engl J Med 2007;356:409-11.

23. Devanlay C, Tavernier-Tardy E, Bourmaud A, Falk AT, Raberin H, Cornillon $\mathrm{J}$, et al. Impact of fluconazole versus posaconazole prophylaxis on the incidence of fungal infections in patients receiving induction chemotherapy for acute myeloid leukemia. Biomed J $2015 ; 38: 235-43$

24. Kohli S, Bhatia S. Evaluation of the color durability of acrylic resin veneer materials after immersion in common beverages at different time intervals: A spectrophotometric study. Biomed J 2015;38:244-9.

25. Chan HL, Thompson A, Martinot-Peignoux M, Piratvisuth $\mathrm{T}$, Cornberg M, Brunetto MR, et al. Hepatitis B surface antigen quantification: Why and how to use it in $2011-$ A core group report J Hepatol 2011;55:1121-31.

26. Liao CC, Hsu CW, Gu PW, Yeh CT, Lin SM, Chiu CT. Comparison of the elecsys HBsAg II assay and the architect assay for quantification of hepatitis B surface antigen in chronic hepatitis B patients. Biomed J 2015;38:250-6.

27. Chen SY, Lu ML, Niu CC, Tsai TT, Liao JC, Chen WJ, et al. Results of instrumented posterolateral fusion in treatment of lumbar spondylolisthesis with and without segmental kyphosis: A retrospective investigation. Biomed J 2015;38:262-8.

28. Bharti JN, Gautam P, Arora P. Neurilemmoma of lateral nasal wall. Biomed J 2015;38:269-70. 